\title{
THE EFFECT OF DIGITAL STORYTELLING ON TEACHER EDUCATION: EXPERIENCES OF PRE-SERVICE TEACHERS
}

\author{
Odeta Norkutė \\ Vytautas Magnus University, Lithuania \\ Vaida Jurgilè \\ Vytautas Magnus University, Lithuania \\ Tetiana Ponomarenko \\ Vytautas Magnus University, Lithuania
}

\begin{abstract}
Digital storytelling (DST) has emerged as a powerful tool in teacher education. However, in Lithuania the effect of this method on pre-service teachers' education has been poorly investigated. The purpose of the current paper is to explore the experience of pre-service teachers in implementing DST method: from idea generation to the final product creation. The novelty of the current research is the usage of DST as a mean for development pre-service teachers' ICT skills together with cooperation skills and creativity. The focus group interview method was implemented in order to collect the data and explore the opinions and experiences of perspective teachers. The research findings demonstrate that the usage of DST contributes to reveal student' insights of future work, familiarizes students with future profession peculiarities, enhances their ability to cooperate, teamwork skills, and facilitates their ICT skills. The results highlight the importance of DST usage in developing perspective teacher's creative personality and capability to interact.
\end{abstract}

Keywords: digital storytelling, teacher education, pre-service teachers.

\section{Introduction}

One of the prerequisites for this study is the development of collaborative capacity through adoption of ICT. The need for this study, related to teacher education, had been induced by the conclusions of different organizations, such as the European Commission, OECD, The United Nations, World Economy Forum (The 10 skills, 2016), which are being formed a new view on the general competencies change. One of the most important skills, emphasized by all organizations, is cooperation. In 2018 The European Committee had renewed the list of lifelong learning skills (2019), where the problem-solving skills and critical thinking were recognized as crucial for coping with challenges of XXI century and were viewed as "work with others in a constructive way, remain resilient and 
Norkute et al., 2020. The Effect of Digital Storytelling on Teacher Education:

Experiences of Pre-Service Teachers

manage one's own learning and career” (Key competences for lifelong learning, 2019, p. 11).

As it was shown in the Program for International Student Assessment (PISA, 2015), the achievements of Lithuanian pupils in this sphere are very scarce, since only 2.5 percent of pupils achieved the highest level of cooperation; hence Lithuania is being rated 31-36 within 51 participating countries. These results show that the amount of time and resources allocated for cooperation skills development are insufficient.

We assume that Lithuanian teachers are not properly prepared to apply diverse means for pupils' cooperation skills enhancement. In the Lithuanian Teacher Training Regulations (2018) there was identified that the educators must develop and deepen their competences such as creativity and problem solving, professional partnerships and digital literacy throughout all his/her active career. This implies that prospective teachers, during their studies, must be given an opportunity to try out a variety of tools to develop their collaborative skills. And one of the most effective ways to solve this issue, offered by the authors of the current study, is the creation of Digital Storytelling in a student group. Moreover, the implementation and possibilities of the Digital Storytelling (DST) in Lithuanian system of pre-service teacher education remain poorly investigated.

The understanding of the prospective teacher's professional identity becomes particularly important in this context. On the one hand, the professional concept of a teacher is shaped by political or organizational requirements (Coggin et al., 2019). On the other hand, depending on various impacts, the teacher develops a personal identity in different forms or attitudes, associated with the emotional content identified by Kearney (2011). It is still quite common to discuss the teacher's professional image with students orally or present their insights in written form. However, in the 21st century, it was decided to combine two important points in the competencies of both students and teachers: to use DST as a learning didactic tool for disclosing and understanding teacher's professional activity.

The present study shows how digital storytelling has been implemented within the pedagogical traineeship (a semester-long practice) of pre-service teachers at a public university. The aim of the current research was to investigate the impact of Digital Storytelling (DST) implementation on the pre-service teacher education, in terms of student skills enhancement. The research questions were the following:

1. How does the implementation of DST impacts the pre-service teachers' cooperation (teamwork, task distribution), communication (interview skills, conflict management) and ICT skills?

2. How does the implementation of DST influence pre-service teachers' cooperation communication and ICT skills? 
3. What barriers were encountered by students while making DST video?

\section{Literature review}

The literature represents the digital storytelling (DST) as a helpful, transformative tool for learners in a range of disciplines and learning contexts. The usage of digital storytelling projects can enrich student learning experience, enhance student sense of autonomy and interactions, especially when they are given an opportunity to demonstrate and discuss their projects (Kearney, 2011). Digital storytelling is a combination of storytelling and digital tools. For example, digital storytelling is characterized by interactivity, nonlinearity, flexible outcomes, user participation, even co-creation. The storytelling can be regarded as a methodology for sharing information, as the digital stories can be created and distributed, and there are possibilities to provide engaging opportunities for scholarship, pedagogy, cross-disciplinary discussion, community building, and distribution of work (Barber, 2016).

According to Robin (2011), the usage of DST in pedagogical activities can be divided into the following groups: (a) personal narratives of significant events; (b) historical films on past events; (c) narratives - information about certain ideas or practices. Although, as Robin (2008) points, many stories combine a variety of traits and it is very difficult to discover pure stories of one type or another, for example, an autobiographical background can become the backdrop for informational storytelling, etc. (Robin, 2008).

The perception of future professional identity is a very important element in prospective teacher studies. According to Ticknor (2014), the professional identity of the educator is quite temporary, awkward, contradictory, full of tension between personal and professional attitudes. And given the 21st century skills and literacy requirements, it is important for teachers to be able to use a variety of tools themselves, while revealing the features of a professional image. One of the tools that can be used to reveal a teacher's professional identity is DST. The application of DST tool in this context was explored by Coggin et al. (2019), who revealed interactions between institutional administrative requirements or limitations and perceptions of personal traits and preferences. Investigating the use of DST in pedagogical studies, the researchers have shown that prospective teachers developed a teacher-centered discourse in which teacher pedagogical power is created through coherence between class and personal relationship (Coggin et al., 2019). Tendero (2006) and Kearney (2011) highlighted the possibility of emotional self-concept disclosure.

In teacher education the "digital storytelling production experiences can be a salient demonstration of engaging with interdisciplinary topics via relevant technological mediums" (Shelton, Archambault, \& Hale, 2017, p. 59). Authors 
Norkute et al., 2020. The Effect of Digital Storytelling on Teacher Education:

Experiences of Pre-Service Teachers

state that the DST making enhances the pre-service teachers' content knowledge and technological skills. In addition, the learners build a deeper understanding and connection to the material, increase their knowledge and skills of video-making process (Shelton et al., 2017).

\section{Methodology}

The purpose of the current paper is to explore the experience of pre-service teachers in implementing DST method: from idea generation to the final product creation. The novelty of the current research is the usage of DST as a mean for development pre-service teachers' ICT skills together with cooperation skills and creativity. The focus group interview method was implemented in order to collect the data and explore the opinions and experiences of perspective teachers. The focus group of 14 groups of preservice teachers produced digital storytelling videos (projects) and was organized in December 2019. The teachers were selected according to their compliance to the goals of the research. Questions for research participants in focus group covered topics about student' insights of future work, familiarizes students with future profession peculiarities, enhances their ability to cooperate, teamwork skills, and facilitates their ICT skills. The focus group interviews were conducted using a semi-structured interview guide.

The interviews lasted approximately $2 \mathrm{~h}$, were recorded on a digital recorder, and transcribed verbatim. All interviews were conducted and analysed in Lithuanian. Themes and quotes were translated to English for presentation of the results. After transcription, the interviews were analysed applying content analysis (Elo \& Kyngas, 2008). The data were read in whole in order to get a sense of the interviews. Then meaning units were identified, coded, and condensed into subthemes and the themes were finally identified. The researchers conducted the analysis process separately and then met to discuss the findings and agreeing on the final themes. New groups of participants were added until data saturation was reached.

\section{Research results}

\section{How does the practice of creating a DST influence pre-service teachers' understanding of their future profession?}

The analysis of the stories revealed 3 thematic areas (Table 1). The prospective teachers were very sensitive to the subtleties of the profession, observing the processes at school and creating the image of the teacher. The general tendency of all stories was to show and communicate to the environment (parents of students, prospective teachers, students who think about enter teaching profession) that the teaching profession is complex, important and significant. 
Table 1 The content of student digital stories

\begin{tabular}{|c|c|c|}
\hline Group of themes & $\begin{array}{c}\text { Title and aims of the digital } \\
\text { stories }\end{array}$ & Title of the digital story \\
\hline \multirow[t]{3}{*}{$\begin{array}{l}\text { Inspiring to become a } \\
\text { teacher/remain in a } \\
\text { profession }\end{array}$} & $\begin{array}{l}\text { Aim: To compare the opinions of } \\
\text { teachers from different generations } \\
\text { in terms of their values, } \\
\text { professional views and beliefs; to } \\
\text { show that teachers of any age are } \\
\text { worthy of admiration. }\end{array}$ & $\begin{array}{l}\text { "Three generations of } \\
\text { teachers" } \\
\text { "The vocation to become a } \\
\text { teacher is timeless" }\end{array}$ \\
\hline & $\begin{array}{l}\text { To demonstrate the positive aspects } \\
\text { of teacher's job, to support teachers } \\
\text { in the media world. }\end{array}$ & $\begin{array}{l}\text { "Inspiring teacher" } \\
\text { "Physically active teacher" } \\
\text { "Do you think to become a } \\
\text { teacher?" }\end{array}$ \\
\hline & $\begin{array}{l}\text { To list all advantages of being a } \\
\text { teacher; to enhance a desire of } \\
\text { students to become teachers; to } \\
\text { prevent teachers' drop out. }\end{array}$ & $\begin{array}{l}\text { "Why is it worthy to be a } \\
\text { teacher?" } \\
\text { "The message to teacher" }\end{array}$ \\
\hline \multirow[t]{2}{*}{$\begin{array}{l}\text { Inspiring teachers to } \\
\text { change }\end{array}$} & $\begin{array}{l}\text { To motivate teachers to be } \\
\text { physically active in order to involve } \\
\text { their students into active and } \\
\text { healthy way of life. }\end{array}$ & $\begin{array}{l}\text { "Physically active teacher" } \\
\text { "The creative teacher" }\end{array}$ \\
\hline & $\begin{array}{l}\text { To analyze and predict what kind of } \\
\text { features the new generation of } \\
\text { teachers will possess? }\end{array}$ & $\begin{array}{l}\text { "Future teachers: } \mathrm{Z} \text { generation } \\
\text { teachers” } \\
\text { „The picture of the responsible } \\
\text { teacher” }\end{array}$ \\
\hline $\begin{array}{l}\text { Teachers' personal } \\
\text { lives/ difficulties of } \\
\text { teacher life }\end{array}$ & $\begin{array}{l}\text { To reveal how do teachers behave } \\
\text { after their working time; to } \\
\text { demonstrate that teachers have the } \\
\text { same concerns, life difficulties and } \\
\text { aspirations as other people. }\end{array}$ & $\begin{array}{l}\text { “Teacher after lessons” } \\
\text { “The portrait of modern } \\
\text { teacher” } \\
\text { "Teacher’s usual working day” } \\
\text { "Teacher to teacher” } \\
\text { "Teacher Jonas has problems” }\end{array}$ \\
\hline
\end{tabular}

This is illustrated by the titles of some stories, such as "Teacher Superhero", "Teacher Inspirer" and "Future Generation Z Teacher". These stories illustrate meaningful aspects of particular importance to modern society: conventional values and vocation ("The vocation to become a teacher is timeless", "Three generations of teachers"). These stories openly reveal the ideas and values of the vocation of the teacher, who have sincerely shared the experience with the audience, pointing out the difficulties, or reluctantly disclosing the first pedagogical experiences.

Another popular theme was the complexity of the teacher's work ("Teacher after lessons", "The portrait of modern teacher", "Teacher's usual working day", "Teacher to teacher", "Teacher Jonas has problems”). The students dared to show themselves the unexpected subtleties of the teacher's work that the teacher 
Norkute et al., 2020. The Effect of Digital Storytelling on Teacher Education:

Experiences of Pre-Service Teachers

does even after school (e.g. simultaneously cooks the dinner and reads a professional literature; checks students' tests at home; face different problems).

The third thematic was the contemporary inspirational example of a teacher ("Inspiring teacher", "Do you think to become a teacher?", "Why is it worthy to be a teacher?", "The message to teacher", "Physically active teacher"). The stories demonstrated how important an inspiring, modern, active teacher is. It can be noted that throughout the stories, the theme of a creative and inspirational teacher dominates. The creators of these stories have chosen very engaging approaches to reveal a modern and inspiring picture of the teacher. For example, using a sense of humor demonstrate how teacher's inspiration can be enhanced by active physical activity, or how nature surrounding helps teacher to gain an inspiration and share it with students.

To sum up the topics of DST we may assert that the thematic of Teacher Portrait offered by the course supervisors, allowed the perspective teachers to set a very clear direction for the creation of digital histories, given the wide variety of DST options available, both thematically and technologically. The storylines did not repeat, meaning that there were broad possibilities for expressing creativity. Moreover, the various technological approaches have been applied: live filming, animation, combination of footage and animation, combination of photos and animation, and utilization of various other sources of video clips.

\section{How does the implementation of DST influence pre-service teachers' cooperation communication and ICT skills?}

The results of student focus groups interviews revealed several main categories related to their experience of creating the digital stories. The experience of cooperation, establishing informal relationship and overcoming difficulties were the most central within students' responses.

Cooperating and learning from each other

The broadest and the most important category of responses implied students' experiences of cooperation and learning from each other. They viewed the cooperation as an inevitable activity helping to find common solutions and enrich their knowledge.

"We have learned to cooperate with each other; learned to listen and hear each other in order to come to the consensus, find a mutual solution, as we are of the different backgrounds and have our own views and opinions. One day we came to have dinner all together $<\ldots>$ everyone expressed their own ideas, applying brainstorming method $<\ldots>$ and after we listed different advantages of teaching, I could not even imagine some of them. It was very advantageous, that we could communicate and fulfill thoughts and bring new ideas to others.” (Group 5)

Some respondents reported about a change in their understanding of the importance of cooperation.

"I thought that the best way is to work alone, but now we are a team and it is very important while creating a film, generating ideas". (G10) 
Therefore, the cooperation between students happened through the search of agreement when there was a need to find a common solution for the certain issues. Working for the achievement of the common goal, the students interacted and promoted their individual and peer learning. Students became more engaged and gained the courage to execute certain tasks.

Overcoming difficulties through cooperation

The establishment of interaction between students contributed not only to enhanced communication, an also to students' abilities to cope with challenges while working together. The respondents reported that the cooperation and mutual support improved their collective confidence and beliefs in the successful accomplishment of the DST assignment. At the very beginning the respondents had experienced the sense of confusion without having a clear focus on certain goals and common understanding of the task. Nevertheless, working in team helped them to overcome the difficulties and engage in a meaningful work.

"At the beginning we were somewhat embarrassed, because we didn't know how to make the assignment. But being in a group, cooperating with each other we did a great job. We realized that everything is possible when you do it in team." (G8)

"We really enjoyed the work. It was challenging, because we did not know how we will work with equipment, how to film - we did not have any experience. But it was challenge, it was very interesting and exciting to see the result. We thought we will never go through, but we did, and we are happy about the results." (G4)

In addition, the students expressed about enhancement of their communication and problem-solving skills, ability to search for compromise and courage to communicate not only within the group of learners, but with potential respondents.

"I have learned how to deal with others, find a compromise and agreement while interviewing teachers, ask for the appointment, communication with teachers.” (G12)

Furthermore, the respondents learned to manage conflicts and search for an agreement through the process of communicative interaction.

"We have learned to understand each other. We discussed a lot, sometimes, there were conflicting situations, but we managed to come to agreement and compromise." (G13)

Allocating time

Some students reported about the improvement of their time planning skills, which was a prerequisite for successful task implementation.

"I think we improved our group work skills, planning the activities, finding mutual solutions. The time planning was crucial for us. We managed to set clear deadlines and keep the pace during all period of DST creation”. (G2)

Some students successfully planned their activities, while others did not manage to establish clear deadlines and communication. Therefore, their DST creation experiences were accompanied by some sense of tension.

"We had a lot of materials and discussed a lot about what pieces to include or exclude.

We were limited in time and there was a kind of pressure to choose the right priorities.

So, we were constantly discussing”. (G1) 
Norkute et al., 2020. The Effect of Digital Storytelling on Teacher Education:

Experiences of Pre-Service Teachers

Thus, in order to avoid the possible tension and confusion related to time limits, the group members working on DST must establish clear and rigorous time frames and follow them.

\section{Building informal relationship}

Working on the DST project established and improved students' informal relationship and friendship. Besides, there was a shift from meetings based on communication at university space to meetings in the non-formal environments.

"We were constantly communicating and discussing with each other. We often organized team meetings to discuss the issues, not only at university, but in the public cafes. It has really improved our relationship." (G3)

"We have discovered each other. When filming, we have spent two hours with great people and there was a great weather. The atmosphere was so exciting, we were instantly laughing." (G7)

Another important insight related to communication was establishment of common virtual informal communication spaces (e.g. via messengers) and supporting this communication all day long. As a result, the respondents noted that they were able to cognize the life rhythms of other group members, which enhanced their sense of presence and interpersonal relationship within the group.

"I experienced the work in team, continuous and constant cooperation when we had to dedicate time for this activity. While communicating via messengers with other group members, I realized that I knew their life rhythms, when they come back from work, when they are available online. You feel the life rhythm of your colleagues.” (G11)

Some students experienced a sense of reluctance at the beginning of the DST project, however, later they admitted the positive impact of informal interaction and teamwork and expressed their joy from cooperation.

"O was really inspired by filming the story. At first, I didn’t want to gather somewhere on Saturday, I was so reluctant. But I went, and it was so much fun! When I came home, I did all my assignments with a pleasure. I was so energized.” (G2)

"I wasn't very enthusiastic about this assignment, as I viewed it as a burden. But later I became so excited about this work, I really enjoyed working with my team, doing technical work, getting together with our own children and working while they're playing.” (G6)

As a result, some respondents reported their satisfaction with the results and emotionally expressed their opinion about the DST project, attempting to motivate the potential students:

"If you'll introduce this assignment to other students and they'll be resistant, just tell them my position: Dare! Go! Motivate! Don’t be afraid! I enjoyed very much!” (G16) Developing ICT skills

The students reported about the development of their ICT skills, mainly related to video creating and montage.

"The Windows Movie Maker has a limited number of options, all the rest programs are not free, and you have to use the illegal versions or pay some fee. Those programs have much more options and the product will be much more quality when you use them. The montage of the digital story took four days, working few hours a day.” (G15) 
Although the DST project assignment implied a development of a broad range of competencies, some students reported the enhancement of their ICT skills as the most valuable and important.

"I have learned to use the software for making the digital stories, and it was the most important advantage of this task. I did not enjoy the groupwork very much.” (G3)

We assume the importance of this competence for perspective teachers, as they will be dealing with a new generation of children which require much broader involvement of ICT into teaching and learning process.

Enacting creativity for emotional content

Some groups of students supported their films with appropriate technologies, diversified with sound and video effects, while other groups simply compelled the whole films of its pieces. Some DST projects included usage of humor for representing the body images and for highlighting certain aspects of teachers' lives. Nonetheless, some respondents admitted that the bringing the creative solutions into their work required a significant amount of time and effort.

"There was a lot of work. I've spent one evening in order to learn how to montage the story, because I have never done that before. At first, I had to receive the information and think, how to represent it in a movie. We need to be creative to make things easier." (G16)

Distributing responsibilities

The task distribution was recognized as a prerequisite for establishing an effective and successful communication. Despite we expected wider involvement of all group members into film creation procedure, most groups claimed that only one person was responsible for the montage, while others were mostly involved into data collection and filming process.

"I liked that in our team we had a person who edited all the pieces we've sent. It was very efficient way of working, when one person was responsible for montage and others could send the materials. It was easier”. (G9)

"We have distributed the duties: some were responsible for sound, montage, filming. Everyone did the job they were good at." (G3)

The respondents stated that the montage work could be a field of possible conflicts where the opinions of creators could not coincide leading to the contradictions and clashes. Therefore, the relationship between teamwork and montage work remains questionable in terms one's accepting of own role and understanding of the roles of others. Nevertheless, distributing tasks helped to overcome the potential conflicts and establish an effective communication.

\section{What barriers were encountered by students while making DST video?}

Facing technical issues

This group of barriers mainly refers to students' concerns while facing issues in finding the appropriate software, obtaining a quality equipment for filming and audio taping.

"We had some issues with filming equipment, because we were filming using our smartphone cameras, that is why we were concerned about the quality of video and audio materials. We wanted to create a really good product.” (G4) 
Norkute et al., 2020. The Effect of Digital Storytelling on Teacher Education:

Experiences of Pre-Service Teachers

As a result, students experienced a sense of uncertainty and confusion, which led to feeling of incapability to achieve the goal. Moreover, they were expected a greatest supervisor's control about this issue.

\section{Feeling incapable}

The lack or complete absence of experience in DST making led to decreased motivation and reluctance at the beginning of DST implementation. The students knew what they wanted to do, however, they did not know how to implement all their plans.

"It was a new experience for me, and the most difficult was to start doing the assignment.

I didn't know where to start and how should it look like at the end.” (G10)

"We needed to find the golden middle. We had many thoughts from the very first day, but we didn't know how to implement all our ideas." (G7)

And the support of supervisors was crucial in both coordinating and directing student ideas and efforts, especially during the first stages of the DST implementation.

"Because it was our very first time, we had a sense of suspense, as we were uncertain what will be the result and how we're going to achieve it. Perhaps, the film montage looked frightening. But the support and advices of supervisors were helpful. We found the right way and now, we are satisfied with the result." (G8)

Selecting the relevant information

The respondents admitted the certain level of difficulty related to selection of appropriate information for the DST film. After filming and taping the materials, the students received huge amounts of different data, which had to be processed and selected.

"It was quite difficult to select the information, because we collected a lot of data and visual materials. We had to be very precise about the goal of our work and select the information in accordance to it. It took 1.5 month to select all the materials and two days to montage the film.” (G5)

The data processing was time consuming and required a significant amount of effort. Moreover, the time constraints (the DST had to be about 4 minutes long) caused an additional tension from one point; however, they provided a clear timeframes and guidance for the final product from another point.

\section{Discussion}

Digital story telling in teacher education is an effective way of providing the necessary skills that can then transfer into real self-directed pedagogical activities. Although one of the essential tasks of the research was to enable students to learn how to use this learning tool, the topic of the Teacher's Image allowed to reveal the features of the emerging professional identity. The themes of the stories created by students, have shown that some certain type of DST is unlikely to be applicable to the disclosure of a professional identity, as this element encompasses a wide range of emotional and subject matter aspects. Namely, the theme of the 
narrative "The Teacher's Image", presupposes the assumptions of identity perception. It is noted that the narratives created by students were primarily dominated by highlighting the positive values or traits of teachers' personalities. Unlike in other studies studies, there is little emphasis on the bureaucratic aspects, political or organizational requirements or restrictions. The dominant feature of the stories is the emotional content - teacher feelings, difficulties, moods. This may be explained by the fact that this task was implemented at the very beginning of the study, when many things were new, unknown and undisclosed. Contrary to other studies, however, the stories did not really reveal signs of tension, major contradiction, or any kind of temporality. This is because the students of pedagogical studies have a strong commitment for pedagogical work, they perceive difficult situations, but in their narratives usually tend to speak not about problems, but about their solutions. Another feature of the narrative is the disclosure of certain didactic approaches, although this aspect remained poorly developed. Perhaps, if the task would be formulated in a different way, such as "Teacher in the classroom" or "Teacher in the lesson", the students produce a more detailed disclosure of didactic decisions.

There were several barriers to the digital story telling in teacher education, such as technical barriers because students encountered a software problem. The lack of experience and motivation was also clearly stated, although ideas were generated smoothly. The students also considered the barrier that it was difficult to select the information accordingly. However, these barriers were not highlighted and were mentioned as improved aspects in the future.

\section{Conclusions}

In summary, the Digital Storytelling project implementation in pre-service teacher education opens broad possibilities for enhancement of student cooperation and learning engagement. However, the attention must be payed to the details of the process organization, and the role of course supervisor here is crucial. Students need to gain clear guidelines and establish effective communication in order to benefit from full collaboration and peer learning.

The research revealed that the DST creation process is an effective mean and tool, which includes several procedural steps leading to the complex acquisition of pedagogical competence. Even though it was the first attempt to implement this tool, the results demonstrate that its realization helps the perspective teachers to understand how collaborative processes should be developed for quality products creation. There is a need for further research on how digital storytelling project could be implemented during the in-service practice of perspective teachers. In addition, the further research could be done on how the DST may be used to build teacher critical thinking and agency for school/teaching improvement. 
Norkute et al., 2020. The Effect of Digital Storytelling on Teacher Education:

Experiences of Pre-Service Teachers

\section{References}

Barber, J.M. (2016). Digital storytelling: New opportunities for humanities scholarship and pedagogy. Cohent Arts \& Humanities, 3, http://dx.doi.org/10.1080/23311983. 2016.1181037

Coggin, L.S., Daley, Sh., Sydnor, J., \& Davis, T.R. (2019). Imagining my ideal: a critical case study of digital storytelling as reflective practice. Reflective Practice, 20(2), 143-159. DOI: 10.1080/14623943.2018.1538949

Kearney, M. (2011). A learning design for student-generated digital storytelling. Learning, Media and Technology, 36(2), 169-188. DOI: 10.1080/17439884.2011.553623

Key competences for lifelong learning. (2019). Luxembourg: Publications Office of the European Union, 11. DOI:10.2766/291008 NC-02-19-150-EN-C.

Ministry of Education, Science and Sport of the Republic of Lithuania. (2018). Teacher Training Regulations. Vilnius.

PISA 2015 Results (Volume V). Collaborative Problem Solving, 70 - 87. DOI: https://dx.doi.org/10.1787/9789264285521-en

Robin, B.R. (2008). Digital Storytelling: A Powerful Technology Tool for the 21st Century Classroom, Theory Into Practice New Media and Education in the 21st Century, 47(3), 220-228. DOI: 10.1080/00405840802153916

Robin, B. (2011). The educational uses of digital storytelling. Proceedings of Society for Information Technology \& Teacher Education International Conference 2006. https://www.researchgate.net/publication/228342171_The_educational_uses_of_digital _storytelling

Shelton, C.C., Archambault, L.M., \& Hale, A.E. (2017). Bringing digital storytelling to the elementary classroom: video production for preservice teachers. Journal of Digital Learning in Teacher Education, 33(2), 58-68. DOI:10.1080/21532974.2016.1276871

Ticknor, A.S. (2014). Negotiating professional identities in teacher education: A closer look at the language of one preservice teacher. The New Educator, 10(4), 289-305. Retrieved from https://doi.org/10.1080/1547688X.2014.965094

World Economic Forum. (2016, Jan 19). The 10 skills you need to thrive in the Fourth Industrial Revolution. (2016). Retrieved from https://www.weforum.org/agenda/2016/01/the-10skills-you-need-to-thrive-in-the-fourth-industrial-revolution/ 